\title{
Prolactin Counteracts Effects of Short Day Lengths on Pelage Growth in the Meadow Vole, Microtus pennsylvanicus
}

\author{
LAURA SMALE, THERESA M. LEE, RANDY J. NELSON, AND \\ IRVING ZUCKER \\ Department of Psychology, University of California, Berkeley, \\ California 94720
}

\begin{abstract}
To test whether growth of the winter coat in short day lengths is contingent on suppression of plama prolactin (Prl) levels, female meadow voles (Microtus pennsylvanicus) were kept in short day lengths for 12 weeks and were injected daily with saline or Prl; long-day animals were treated with either the dopamine agonist, bromocryptine (bromo), bromo plus Prl, or saline. Prl treatment prevented the growth of the winter coat normally observed after 12 weeks in short day lengths, but bromocryptine did not stimulate pelage growth in long-day voles. Pelage growth in short day lengths appears contingent upon decreased plasma prolactin levels.
\end{abstract}

Coordinated physiological and behavioral changes occur in meadow voles (Microtus pennsylvanicus) exposed to short day lengths ( $10 \mathrm{~h}$ light/ day). Food intake and body weight decline, testes regress, brown fat mass increases, nest building increases, and the pelage becomes longer and thicker (Dark and Zucker, '83, '85; Lee et al., ' $87 \mathrm{a}, \mathrm{b})$. These changes are thought to promote winter survival by decreasing energy requirements.

In other mammals, seasonal changes in plasma prolactin (Prl) levels are associated with seasonal pelage cycles (sheep: Allain et al., '86; foxes: Smith et al., '87; Siberian hamsters: Duncan and Goldman, '83, '85; mink: Martinet and Allain, '85; deer: Webster and Barrell, '85). In mink and Siberian hamsters, short day lengths decrease plasma prolactin levels and trigger the molt to a winter pelage; the winter molt does not occur if prolactin is maintained at artificially high levels (Duncan and Goldman, '84; Martinet et al., '84). The molt to a summer pelage is blocked in Siberian hamsters and foxes if the normal rise in prolactin titers is prevented with injections of the dopamine agonist bromocryptine (bromo; Duncan and Goldman, '84; Smith et al., '87).

Among meadow voles, lactation counteracts the effects of short day lengths on pelage (Lee et al., '87b), suggesting that Prl may be an important factor controlling molt. In the present study, we tested this hypothesis by observing the effects on pelage of artificially raising Prl titers of voles kept in a short photperiod, and by attempting to suppress prolactin levels in long-day voles.

\section{MATERIALS AND ME'THODS}

Sixty adult female meadow voles from an outbred laboratory colony were housed singly in 32 $\times 21 \times 12.5 \mathrm{~cm}$ metal cages, maintained at $23 \pm$ $2^{\circ} \mathrm{C}$ in a room illuminated with $14 \mathrm{~h}$ of light/day (long day, LD 14:10; lights on at $0700 \mathrm{~h}$ daily) and provided with food (Purina diet \#5015) and tap water ad libitum.

Voles were assigned to one of five groups matched for body weight $(n=12 /$ group $)$ and treated as follows: 1) SD-P: maintained in a short photoperiod (LD 10:14; lights on at $0700 \mathrm{~h}$ ) and injected daily with $0.2 \mathrm{mg}$ ovine Prl (National Pituitary Agency) dissolved in $0.05 \mathrm{ml} 0.9 \%$ saline. 2) SD-S: maintained in the short photoperiod and injected daily with $0.05 \mathrm{ml}$ saline. 3) LD-B: maintained in the long photoperiod and injected daily with $0.2 \mathrm{mg}$ of the dopamine agonist bromocryptine (CB-154; Sandoz Pharmaceuticals) in $0.05 \mathrm{ml}$ saline. 4) LD-B + P: maintained in the long photoperiod and injected daily with $0.2 \mathrm{mg}$ CB-154 + $0.2 \mathrm{mg}$ ovine $\mathrm{Prl}$ in $0.05 \mathrm{ml}$ saline. 5) LD-S: maintained in the long photoperiod and injected daily with $0.5 \mathrm{ml}$ saline. Treatments were continued for 12 weeks. Injections for all groups were between 1200-1500 h daily.

\footnotetext{
Received May 10, 1989; accepted August 9, 1989.

Theresa M. Lee's present address is University of Michigan Neuroscience Lab Building, 1103 E. Huron, Ann Arbor, MI 481041687. Address reprint requests there.

Laura Smale's present address is Keekorok Lodge, Box 47557, Nairobi, Kenya.

Randy J. Nelson's present address is Johns Hopkins University, Department of Psychology, 20C Ames Hall, Baltimore MD, 21218.
} 
At the end of the study, a lethal injection of sodium pentobarbital was administered. Fur depth was recorded as the distance from the skin to the surface of the pelage $( \pm 0.1 \mathrm{~mm})$. Hair density was obtained by shaving and weighing a 1 $\mathrm{cm}^{2}$ patch of fur (Al-Khateeb and Johnson, '71) and underhair and guard hair lengths were measured with a micrometer $( \pm 0.1 \mathrm{~mm})$. A small patch of shaved skin $\left(2 \mathrm{~cm}^{2}\right)$ was removed, stored in $10 \%$ formalin, embedded in paraffin, sectioned at $5 \mu \mathrm{m}$, and stained with hematoxylin and eosin. The average number of follicles in ten intact follicular bundles was determined microscopically for each animal. All pelage measures were obtained from the posterior dorsal surface by an individual uninformed about the experimental condition of the animal.

Treatment effects on follicle number were evaluated with an ANOVA and the other pelage measures with a multivariate ANOVA (Systat, Inc). Differences were considered significant if $P<$ 0.05 . Bonferroni comparisons with Tukey HSD were used for post hoc tests.

\section{RESULTS}

All measures were affected by treatment condition (Table 1). Exposure to short day lengths substantially increased fur depth, density, guard hair and underhair lengths, and follicle number among saline-injected control animals (SD-S vs. LD-S; Table 1). The increase in fur depth, density, and guard hair length normally observed for animals in short day lengths were all blocked by daily injections of Prl, so pelage of SD-P voles differed significantly from that of $\mathrm{SD}$ animals treated with saline (Table 1). Pelage characteristics of SD voles treated with Prl were similar to those of $L D$ voles treated with saline. By contrast, the influence of short days on underhair length and follicle number was not significantly affected by Prl treatment (SD-S vs. SD-P; Table 1). Both of these measures were intermediate between SD-S and LD-S values, and short-day Prl-treated animals did not differ from long-day controls with respect to any measure of pelage development (SD-P vs. LD-S; Table 1). No differences were observed with respect to any measure of pelage development among the three long-day groups (LDS, LD-B, LD-B + P; Table 1).

\section{DISCUSSION}

Daily injections of $\mathrm{Prl}$ prevented development of a winter pelage in meadow voles housed in short day lengths. Every measure of pelage growth was increased in control animals maintained in short as compared to long days. Increases in fur depth, fur density, and guard hair length were counteracted in short-day voles treated with prolactin, thereby supporting the hypothesis that the autumnal decline in plasma prolactin titers mediates pelage changes.

Low levels of Prl may be an important permissive factor in the development of a winter pelage. Alternatively, decreases in Prl secretion may trigger the winter molt. We attempted to distinguish between these alternatives by injecting long-day animals with bromocryptine, an agent that suppresses prolactin secretion in many mammalian species ( $\mathrm{Lu}$ et al., '71). In this study, bromo did not affect any measure of pelage growth. A subsequent experiment established, however, that the dosage of bromo $(0.2 \mathrm{mg} /$ day $)$ injected for 1 week was without effect on Prl titers of female meadow voles housed in long-day lengths; $\operatorname{Prl}$ titers were indistinguishable for animals injected with saline $(\mathrm{n}=10,65.4 \pm 14.3 \mathrm{ng} /$

$T A B L E$ 1. Pelage measurements (mean $\pm S E M)^{1}$

\begin{tabular}{lcccrr}
\hline & SD-S & SD-P & LD-S & LD-B & LD-B +P \\
\hline $\begin{array}{l}\text { Depth } \\
(\mathrm{mm})\end{array}$ & $7.4 \pm 0.3^{*}$ & $6.5 \pm 0.3^{* *}$ & $6.0 \pm 0.1$ & $6.2 \pm 0.2$ & $6.1 \pm 0.2$ \\
$\begin{array}{c}\text { Density } \\
(\mathrm{mg} / \mathrm{cc})\end{array}$ & $54.4 \pm 3.5^{*}$ & $40.7 \pm 2.6^{* *}$ & $38.5 \pm 2.5$ & $38.2 \pm 2.3$ & $33.0 \pm 2.5$ \\
$\begin{array}{c}\text { Underhair } \\
(\mathrm{mm})\end{array}$ & $12.6 \pm 0.4^{*}$ & $11.8 \pm 0.4$ & $10.9 \pm 0.3$ & $10.9 \pm 0.4$ & $11.2 \pm 0.3$ \\
$\begin{array}{c}\text { Guard hair } \\
(\mathrm{mm})\end{array}$ & $17.2 \pm 0.4^{*}$ & $15.1 \pm 0.5^{* *}$ & $15.5 \pm 0.2$ & $15.1 \pm 0.3$ & $15.4 \pm 0.4$ \\
$\begin{array}{c}\text { Follicles } \\
(\text { No./bundle) }\end{array}$ & $8.6 \pm 0.3^{*}$ & $7.9 \pm 0.3$ & $7.0 \pm 0.5$ & $7.0 \pm 0.3$ & $7.6 \pm 0.4$ \\
\hline
\end{tabular}

${ }^{1}$ See text for abbreviations.

${ }^{2}$ Overall MANOVA $P<0.05$.

${ }^{3}$ Overall ANOVA $P<0.05$.
*Differs significantly from all long-day groups.

** Differs significantly from SD-S. 
$\mathrm{ml})$ and bromo $(\mathrm{n}=9,62.1 \pm 17.8 \mathrm{ng} / \mathrm{ml})$, respectively (Lee and Nelson, unpublished observations generated by daily injections of either saline or bromo in LD, virgin females, 60 days of age, for 5 days prior to plasma collection. Prl assay generated against a curve for meadow voles with $\mathrm{Na}$ tional Pituitary Agency Rat Prl). Among Djungarian hamsters, the effect of bromo on both Prl and molt is more pronounced in short- than long-day lengths; it has been suggested that in long-day lengths the effects of bromo may be overridden by a Prl-releasing factor (B.D. Goldman, personal communication). A similar mechanism could account for failure of bromo to influence Prl or molt in meadow voles. It is, however, still unclear whether low levels of Prl are sufficient, or merely necessary, for the winter molt in meadow voles.

Exogenous Prl administered to short-day voles affected some pelage characteristics more than others; thus, neither underhair length nor the number of follicles per follicular bundle was significantly increased in Prl-treated animals. The values obtained were intermediate between those of short- and long-day voles. Perhaps development of winter pelage in short-day animals would have been completely blocked had the Prl injections more closely simulated the normal pattern of Prl secretion in long-day voles. It remains possible, however, that different parameters of pelage growth are controlled by different physiological mechanisms. In meadow voles, the growth of underhairs appears to be a pineal-independent response to short day lengths whereas shortphotoperiod-induced increases in guard hair length, fur density, and fur depth all depend on the pineal gland (Smale et al., '88). The failure of Prl to significantly affect underhair length in this study may, therefore, be another indication that photoperiodic control of this characteristic operates in a manner quite different from the mechanism controlling other parameters of the winter molt.

\section{ACKNOWLEDGMENTS}

We thank Chris Tuthill and Lisa Higa for histology and maintenance of the animal colony and Mandy Bauman for animal care. Prolactin was donated by the National Pituitary Agency and bromocryptine was a gift of the Sandoz Corporation. This research was supported by grants HD02982, HD-24575, and HD-22201 from the National Institute of Child Health and Human Development.

\section{LITERATURE CITED}

Al-Khateeb, A., and E. Johnson (1971) Seasonal changes of pelage in the vole (Microtus agrestis) I. Correlation with changes in the endocrine glands. Gen. Comp. Endocrinol., 16:217-228.

Allain, D., J.P. Ravault, B.A. Panaretto, and J. Rougeot (1986) Effects of pinealectomy on photoperiodic control of hair follicle activity in the limousine ram: Possible relationships with plasma prolactin levels. J. Pineal Res., 3:25-32.

Dark, J., and I. Zucker (1983) Short photoperiods reduce winter energy requirements of the meadow vole, Microtus pennsylvanicus. Physiol. Behav., 31:669-702.

Dark, J., and I. Zucker (1985) Seasonal cycles in energy balance: Regulation by light. Ann. NY Acad. Sci., 453:170181.

Duncan, M.J., and B.D. Goldman (1983) Photoperiodic regulation of prolactin levels may mediate the annual pelage color cycle in the Djungarian hamster (Phodopus sungorus sungorus): Mediation by melatonin. Endocrinilogy, 113: 1268-1273.

Duncan, M.J., and B.D. Goldman (1984) Hormonal regulation of the annual pelage color cycle in the Djungarian hamster, Phodopus songorus, II. Role of prolactin. J. Exp. Zool., 230:97-103.

Duncan, M.J., and B.D. Goldman (1985) Physiological doses of prolactin stimulate pelage pigmentation in Djungarian hamster. Am. J. Physiol., 17:R664-R667.

Lee, T., L. Smale, I. Zucker, and J. Dark (1987a) Role of photoperiod during pregnancy and lactation in the meadow vole, Microtus pennsylvanicus. J. Reprod. Fertil., 81:343350.

Lee, T., L. Smale, I. Zucker, and J. Dark (1987b) Interaction of daylength and lactation in the control of pelage and nestbuilding in female meadow voles, (Microtus pennsylvanicus). J. Reprod. Fertil., 81:351-356.

Lu, R. H., F. Koch, and J. Meites (1971) Direct inhibition by ergocornine of pituitary prolactin release. Endocrinology, 89:229-233.

Martinet, L., D. Allain, and C. Weiner (1984) Role of prolactin in the photoperiodic control of moulting in the mink (Mustela vison). J. Endocrinol., 103:9-15.

Martinet, L., and D. Allain (1985) Role of the pineal gland in the photoperiodic control of reproductive and nonreproductive functions in mink (Mustela vison). In: Photoperiodism, Melatonin and the Pineal. D. Evered and S. Clark, eds. Ciba Foundation Symposium 117, Pittman, London, pp. 170185.

Smale, L., J. Dark, and I. Zucker (1988) Pineal and photoperiodic influences on fat deposition, pelage and testicular activity in male meadow voles. J. Biol. Rhythms, 3:349355.

Smith, A.J., M. Mondain-Monval, P. Simon, K. Andersen Berg, O.P.F. Clausen, P.O. Hofmo, and R. Scholler (1987) Preliminary studies of the effects of bromocriptine on testicular regression and the spring moult in a seasonal breeder, the male blue fox, (Alopex lagopus). J. Reprod. Fertil., 81:517-524.

Webster, J.R., and G.K. Barrell (1985) Advancement of reproductive activity, seasonal reduction in prolactin secretion and seasonal pelage changes in pubertal red deer hinds (Cervus elaphus) subjected to artificially shortened daily photoperiod or daily melatonin treatments. J. Reprod. Fertil., 73:255-260. 